\title{
ARTICLE
}

\section{Open Access in UCL: a new paradigm for London's Global University in research support}

\author{
Paul Ayris, Martin Moyle, Erica McLaren, Catherine Sharp, Lara Speicher \\ UCL Library Services and UCL Press
}

\begin{abstract}
Open Access provides an opportunity for researchers to disseminate their research globally, but it comes with challenges. This article looks at the various ways in which UCL (University College London) has addressed those challenges, by investing in Open Access activities at the university.
\end{abstract}

\section{Keywords}

Open Access, UCL, institutional repository, research, scholarly publishing, article processing charges

\section{Introduction}

UCL (University College London, www.ucl.ac.uk) is London's Global University. It is ranked $4^{\text {th }}$ in the 2013/14 QS World University rankings. The purpose of this article is to demonstrate how a research-intensive university sees Open Access (OA) to publications as an opportunity not a threat. UCL has invested in OA policy development, repository construction, the payment of Gold Article Processing Charges (APCs) for authors and the establishment of an OA University Press to underline its commitment to innovative ways in making UCL's research and knowledge available to a global community.

\section{UCL Open Access policy development}

\section{The European policy context}

The LERU (League of European Research Universities) Roadmap Towards Open Access (LERU, 2011) sets the context for Open Access discussions in 21 European research universities, which include UCL. Founded in 2002, LERU advocates education through an awareness of the frontiers of human understanding; the creation of new knowledge through basic research, which is the ultimate source of innovation in society; and the promotion of research across a broad front in partnership with industry and society at large.

The purpose of the League is to advocate these values, to influence policy in Europe and to develop best practice through mutual exchange of experience. LERU regularly publishes a variety of papers and reports that make high-level policy statements, provides in-depth analyses and makes concrete recommendations for policymakers, universities, researchers and other stakeholders. 
The Roadmap identifies a number of advantages in an Open Access position. The institutional advantages are that Open Access provides a front-end to the whole of a university's research output and supports marketing for a university's offering across the globe. Open Access can also aid in the recruitment of research students who become aware of research activity at the institution via web searches. There are also personal benefits to researchers such as the citation advantages for those who disseminate in Open Access and the tracing of impact via altmetrics. There are benefits for society as a whole, as communities outside higher education, such as small and medium enterprises (SMEs), are able to view blue-skies research and applied research relevant to their particular business. This in turn can lead to consultancy or further research for the academic. Finally there are the political benefits in that decision and policy makers have full access to a university's research.

\section{UCL Open Access mandate}

UCL has an Open Access mandate, which was steered through Academic Board - the senior academic committee in UCL - and is enshrined in the UCL Publications Policy (www.ucl.ac.uk/library/publications-policy.shtml). UCL Academic Board, in May 2009, agreed two principles to underpin UCL's publication activity and to support its scholarly mission:

1. That, copyright permissions allowing, a copy of all research outputs should be deposited in the UCL institutional repository (UCL Discovery) as Open Access

2. That individual UCL academic researchers should be directly responsible for providing and maintaining details of their publications in relevant UCL databases so as to support both Open Access and the requirement for UCL to keep an accurate record of its research outputs

It was also agreed that the Open Access Strategy should be embedded in the pan-University strategies for research, copyright, teaching and learning, and in UCL an Open Access approach is reflected in all these institutional policies. The Staff Copyright Policy (www.ucl.ac.uk/library/scholarly-communication/ipr.shtml) is fully permissive of Open Access approaches, if that is the route that academics wish to take. It does not explicitly advocate an Open Access position for research outputs, however, since copyright lies with the author, and is set in the policy as a waiver by UCL of its rights. This is an aspect of academic freedom that UCL greatly values.

\section{Green and Gold routes towards Open Access}

The two most common forms of open access are commonly referred to as green or gold open access. Green is where authors publish their work in a traditional subscription journal and then self deposit (sometimes referred to as self archive) that work on their own web sites or in an institutional disciplinary repository from where readers freely access the work. Gold open access refers to papers that are freely available on publication, so do not require payment of a subscription by a library or other organisation or individual to enable readers to access the content. Instead the author, their employer or funder pays an APC or universities, other research organisations or learned societies subsidise gold publication by providing staffing and infrastructure for journal production and no APCs are charged. An emerging iteration of gold open access is the hybrid journal where traditional journals offer authors the option of making their papers open access upon payment of a fee. Paying an APC in a hybrid journal only makes one article available - the rest of the journal must still be accessed by subscription.

Institutional repositories provide a basis for Open Access approaches along the Green route. Costs vary from $€ 30,000$ - $€ 242,000$ per year in the UK (LERU, paragraph 22, 2011). Authors should not assign their copyright to publishers. A better model is for authors to grant non-exclusive rights to a publisher to publish. 
The LERU Roadmap notes that Sustainable Business Models for Gold Open Access publishing need to be developed. The two main models that currently exist are fully Open Access journals and hybrid journals which allow APCs. However, there is a problem of 'differential pricing' (commonly known as 'double dipping') when both subscription charges are levied for journal subscriptions and an APC is raised by a publisher to make an article Open Access.

The issue of Open Access costs has been examined by Professor John Houghton and Dr Alma Swan (2012). Their modelling shows that if all universities worldwide adopted Open Access tomorrow, the whole scholarly communications workflow would deliver savings for institutions - these savings are greater if the Gold route is followed, rather than the Green. However, the reality is that the world will not turn Open Access tomorrow. In this case, there are costs not savings for universities in following an Open Access route. The costs are greater for Gold than for Green. The modelling is illustrated in the Figure 1 below.
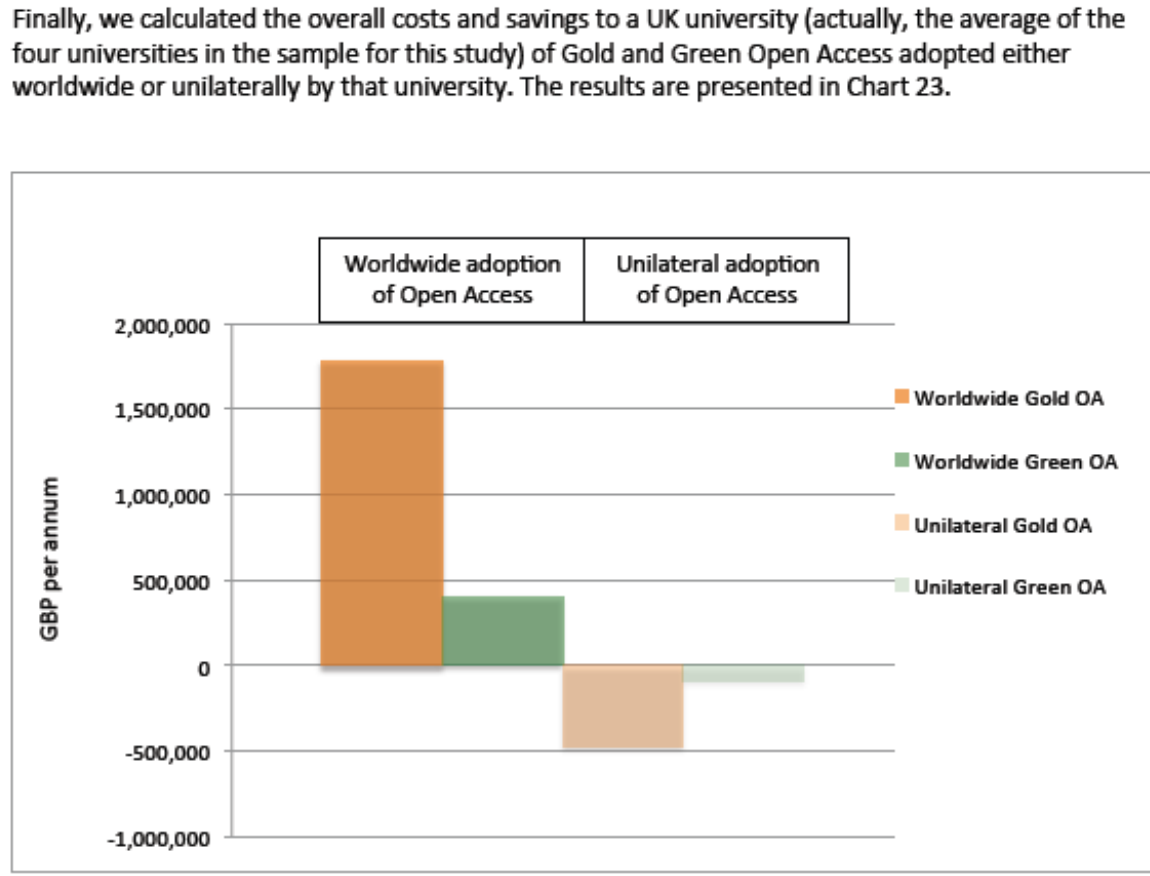

Chart 23: Cost savings to universities of $O A$ alternatives with worldwide and unilateral adoption (calculated using an average of the sample of the four UK universities in this study)

Figure 1: Cost savings for OA alternatives

\section{Finch Report}

The Finch Report (www.researchinfonet.org/publish/finch) represents an important statement on Open Access policy, and it advocates a policy position that has been agreed by UK Government. The Finch Report proposes the Gold route as the route by which Open Access should be progressed in the UK. The Report notes that the UK produces 6\% of world's global research output. For an extra £38 million to UK Higher Education, UK research outputs could be published as Gold OA research outputs. Under a Finch regime, Green Open Access would be for grey literature or theses. UK Universities have strongly contested the policy position adopted by Finch and the UK Government, largely because of the extra costs that they would incur (Poynder 2012a; 2012b). 


\section{Research Councils UK (RCUK) policy}

Research Councils UK (www.rcuk.ac.uk/research/outputs) has issued a policy which is broadly in line with the Finch Report. The RCUK policy supports both 'Gold' and 'Green' routes to Open Access. RCUK, however, has a preference for immediate Open Access with the maximum opportunity for re-use. Their policy requires the adoption of a CC-BY (Creative Commons) licence. CC-BY is one of several licences content creators can apply to their work. In selecting a CC-BY licence content creators enable others to distribute, remix, tweak, and build upon their work, even commercially, as long as the original creators of the work are credited. A range of different licences has been proposed by the Creative Commons organisation ( http://creativecommons.org/licenses/).

For embargoes, RCUK prefers the following periods: 6 months for STEM (Science, Technology, Engineering, Medicine), and 12 months for AHSS (Arts, Humanities and Social Sciences). The preference for Gold is almost unique among European research funders. Gold APC payments are now no longer an allowable cost in Research Council grants. Rather central funds are provided by RCUK to universities to pay for APCs. UCL administers these funds through an OA Team based in the Library. The only other Government that has taken such a position on Gold Open Access is the Dutch, and the present author has issued a rejoinder to this policy position based on the LERU Roadmap (Ayris 2014).

This is the difficulty with Gold OA, particularly hybrid Gold. If subscriptions and APCs are paid for the same article, how do individual universities see any relief on the level of their costs? Lowering subscription costs at a global level does not sufficiently help the individual institution which is meeting the cost of the subscription and the APC. LERU universities produce a lot of research and, under this model, fear they would find themselves paying significantly more.

\section{HEFCE policy for REF (Research Excellence Framework) 2020}

HEFCE (Higher Education Funding Council for England) published its Open Access policy for REF 2020 (www.hefce.ac.uk/whatwedo/rsrch/rinfrastruct/oa/) in Spring 2014. HEFCE is proposing an Open Access requirement for journal articles and conference proceedings, although monographs are exempt. This requirement will start in 2016. There are a number of exceptions to the various requirements that will be automatically allowed by the policy. These exceptions cover circumstances where deposit was not possible, or where Open Access to deposited material could not be achieved within the policy requirements. These exceptions will allow institutions to achieve near-total compliance, but the post-2014 REF will also include a mechanism for considering any other exceptional cases where an output could not otherwise meet the requirements. So central is the funding which UK researchintensive universities enjoy from the REF that any policy position that HEFCE adopts is likely to be a game-changer, probably even more influential than any individual university mandate for Open Access.

\section{Summary of the UK position}

The UK has taken a strong policy position on Open Access, probably the strongest policy position of any member state in the European Union. UCL has an Open Access mandate and led the writing of the LERU Roadmap Towards Open Access (http://www.leru.org/files/publications/LERU_AP8_Open_Access.pdf). The UK Government strongly favours the Gold route for Open Access, whilst research universities favour Green and HEFCE is more open in its assessment of both routes. Certainly, for research-intensive universities in the UK, Open Access compliance is a challenge. What follows in this article is a route map that shows how one university, UCL, has risen to the challenge. 


\section{The role of UCL Discovery in opening UCL research}

\section{Background}

UCL's institutional repository, UCL Discovery (http://discovery.ucl.ac.uk), was established in 2004 as UCL EPrints, using the GNU EPrints platform. The repository initially offered a mediated deposit service, moving to a researcher 'self-archiving' model in 2010. Also in 2010, UCL EPrints was coupled with Symplectic Elements, which was introduced as a publications management system for UCL. The repository was re-branded and re-launched as UCL Discovery in 2011. It hosts metadata for all known UCL publications, with accompanying full text where deposited, and thereby provides a central, open access showcase for UCL research.

\section{Milestones}

Various developments, both internal and external, have helped to raise the profile of UCL Discovery within UCL and extend engagement with it by UCL researchers. There were several important milestones along the way.

In 2008, the Discovery team undertook to include records of every UCL publication submitted to that year's UK RAE (Research Assessment Exercise), extending the content of the service and helping to raise awareness of it. Also in 2008, the deposit of electronic theses in UCL EPrints became a mandatory requirement for all students registering for a UCL research degree, accelerating the growth of full text repository content.

In 2009, a UCL Publications Board, chaired by the Vice-Provost (Research) and including senior Faculty Officers, was established. The formation of the Publications Board marked UCL's recognition of the strategic importance of Open Access to the institution, and provides high-level championship for the repository. The UCL Publications Board sponsored the UCL Publications Policy (www.ucl.ac.uk/library/publications-policy.shtml), adopted in 2009. The Policy includes the principle that a copy of every UCL research output should be deposited and made freely available in UCL Discovery, copyright permissions allowing.

In 2010, Symplectic Elements, implemented locally as the UCL Research Publications System (RPS), was introduced under the auspices of the UCL Publications Board. RPS is a one-stop publications management system, offering UCL researchers the ability to harvest, import or enter publication details; it also provides a simple deposit interface for the upload of full text into UCL Discovery.

Mandates from research funders have been critical in driving researcher engagement with UCL Discovery, in particular the RCUK mandate (www.rcuk.ac.uk/research/outputs/) which came into force in April 2013. All Research Council-funded research must now comply with the RCUK's revised Open Access policy, whether through paid-for open access or manuscript deposit under authors' retained rights. Publications made openly available through either route are available through UCL Discovery, and general awareness of Open Access among UCL researchers has undoubtedly increased.

One long-standing barrier to deposit was a perception that an author's manuscript is a poor substitute for the publisher version of a publication. To overcome such concerns, UCL Discovery introduced in 2013 a 'green re-formatting' service, by which a style template is applied to incoming manuscripts, ensuring a uniform appearance and including pagination markers to aid accurate citation. 
The UCL Discovery team has recently begun systematically to seek and harvest publisher versions of UCL outputs that can legitimately be added to the repository, whether Gold Open Access publications whose licence allows re-use, or publications from subscription journals where copyrights permit dissemination through a repository after a specified embargo period.

\section{Content}

The deposit of full text to meet funding body requirements, deposits from UCL researchers keen to make their research freely available, e-theses deposited as a condition of award, and full text harvested from official sources have together resulted in a steady growth in repository full text content.

Growth in UCL Discovery full text records

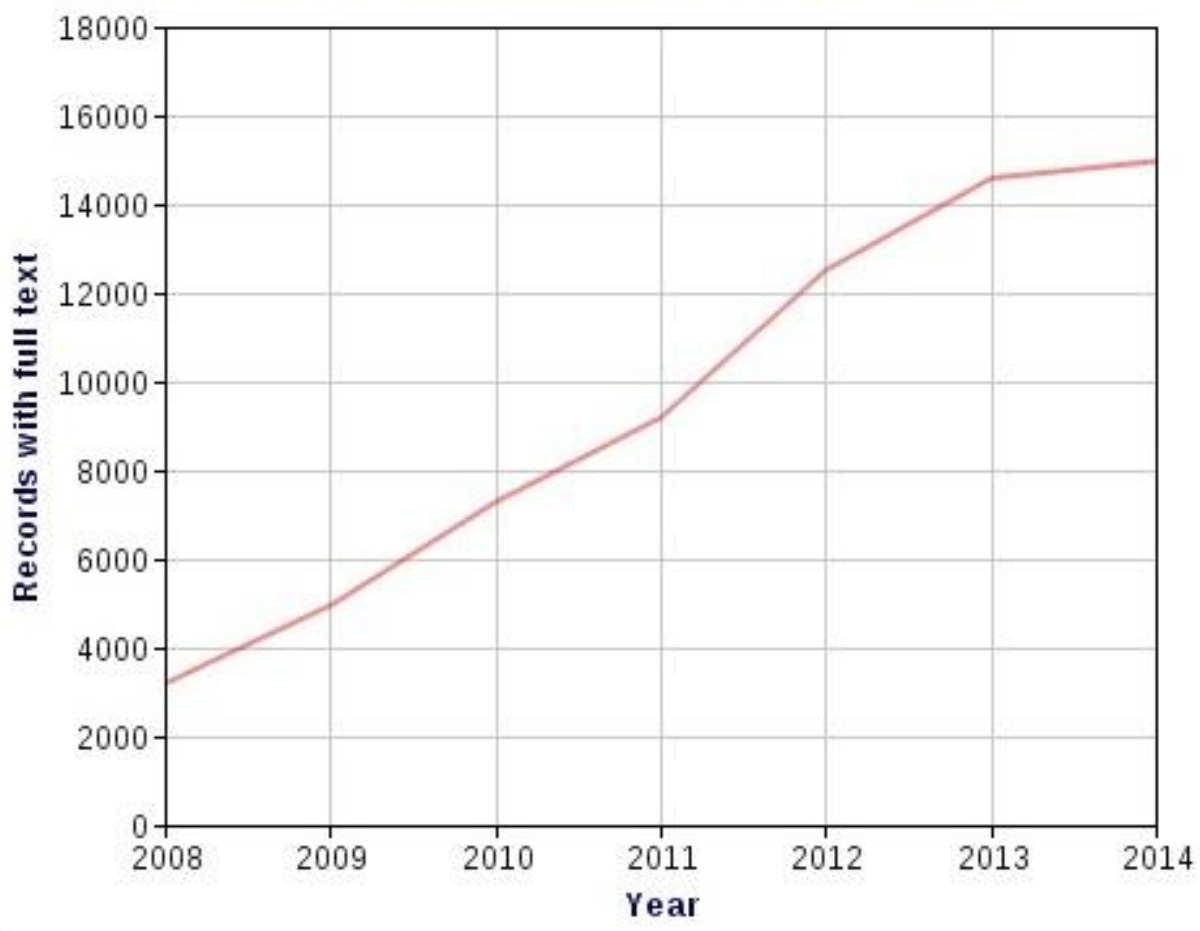

Figure 2: Growth in UCL Discovery full text records 
The number of e-theses deposited has increased since 2008, as shown by the following chart. The download statistics indicate that e-theses are a popular resource: for example, nine of the 'top 20' downloads for February 2014 were e-theses.

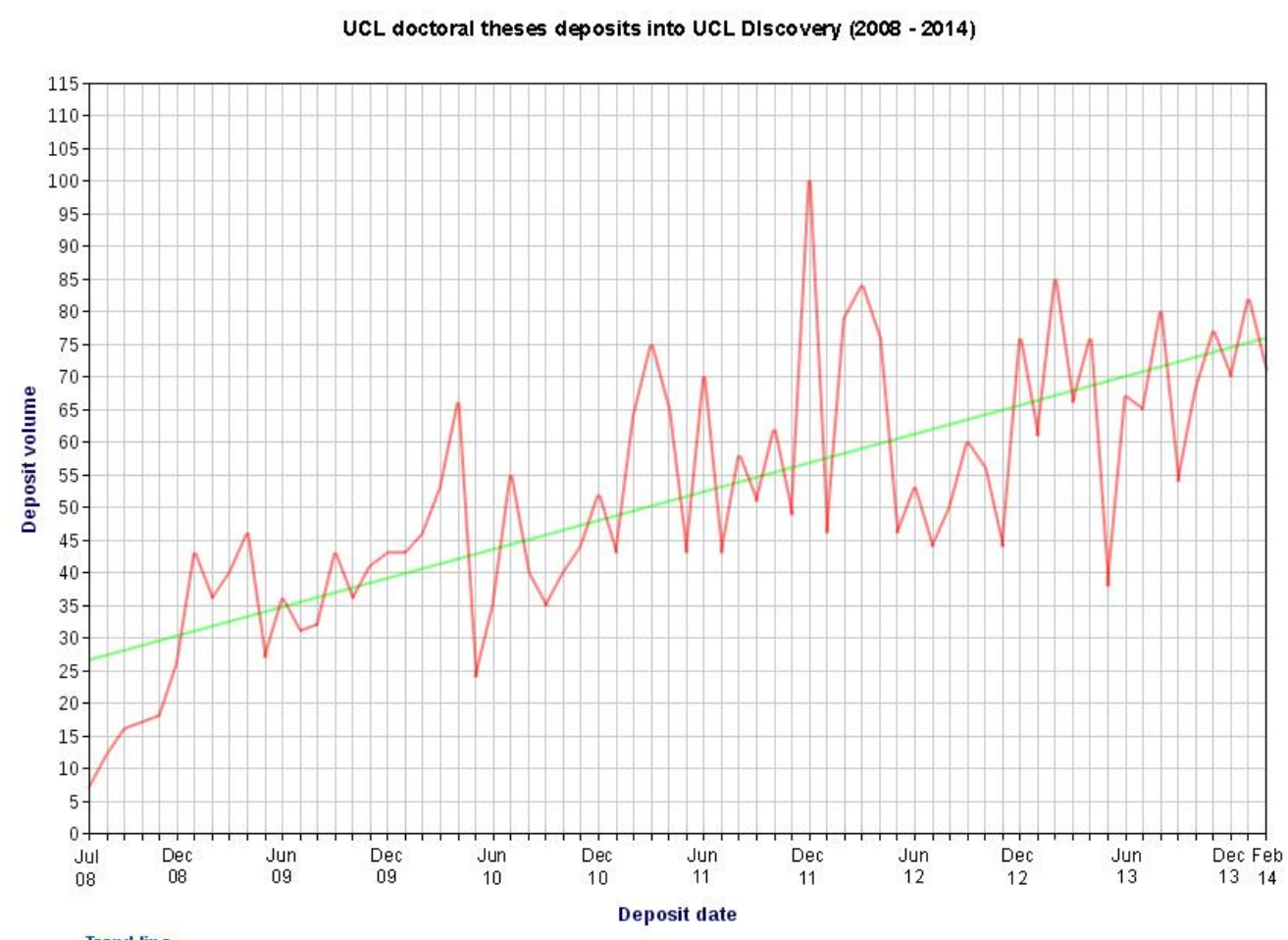

Trend line

Figure 3: UCL doctoral theses deposits into UCL Discovery 2008-14

\section{Visibility}

UCL Discovery downloads are a testament to the visibility of UCL research. Annual download totals have grown from under 200,000 per year in 2008 to over 1.3 million in 2013. In December 2013, UCL Discovery passed the milestone of 4 million lifetime downloads. 
Growth in UCL Discovery downloads (2008 - 2013)

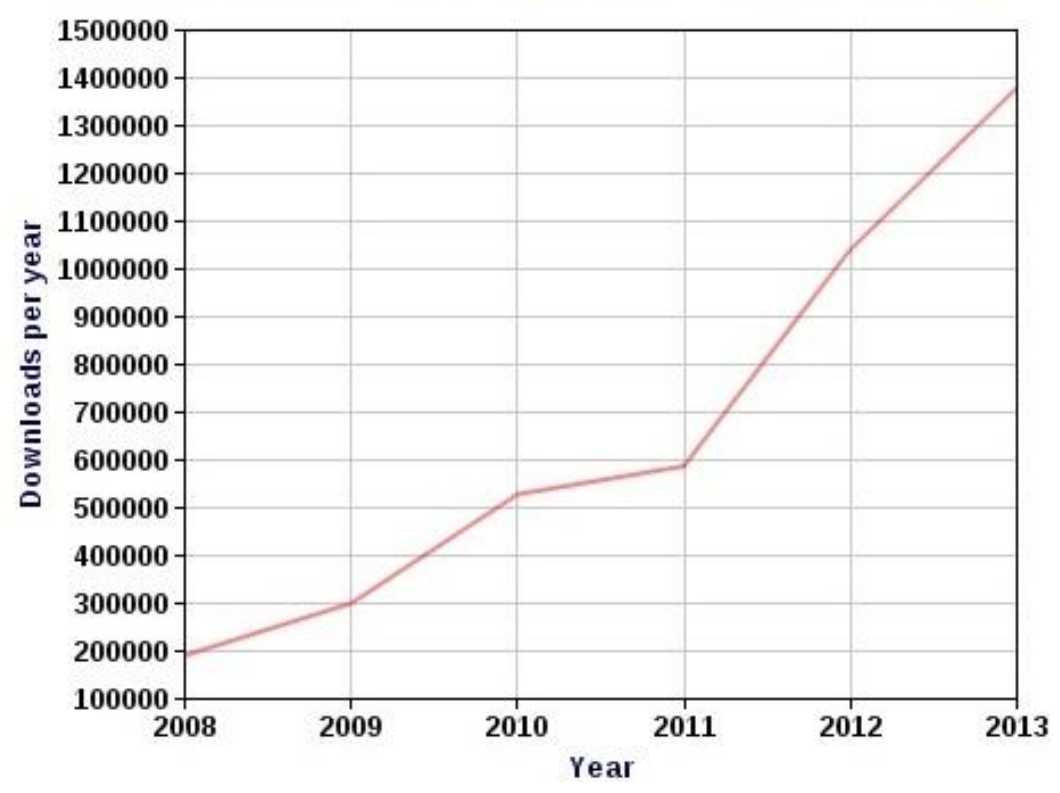

Figure 4: Growth in UCL Discovery downloads (2008-13)

The EPrints platform on which the repository is based has effective search engine optimisation, with relevant UCL Discovery records routinely returning in the first page of search results, usually before equivalent records from official sources or content aggregators. Approximately half of UCL Discovery traffic comes via Google or Google Scholar.

Additionally, a number of external aggregation services harvest data from UCL Discovery. The DART-Europe (www.dart-europe.eu) e-theses portal, for example, collects metadata, including full-text links, about UCL e-theses; relevant papers in economics are contributed to REPEC (Research Papers in Economics - www.repec.org); Ex Libris' PrimoCentral Index aggregates all UCL Discovery content.

The UCL Discovery team also promotes new full text content using Twitter. With an expanding number of followers, there have been positive comments on UCL research and many internal and external re-tweets.

\section{Versatility}

UCL has sought additional return on its investment in UCL Discovery by finding ways to exploit the repository infrastructure and re-purpose its content. For example, UCL Discovery will support UCL Press (see below) by housing an Open Access copy of every UCL Press publication, making it independently discoverable and exposed to search engines and other services. The repository already works in tandem with a local installation of OJS (Open Journal Systems), which provides a journal management layer over UCL Discovery, in which articles are stored and from which they are accessible.

To support teaching and learning, the UCL Discovery team works closely with the ReadingLists@UCL service, which is an on-line repository of UCL reading lists with links to online content. Such content has primarily consisted of externally-hosted books and journal articles and locally-digitised course readings, but the repository is proving to be an excellent source of e-learning material for students, and advocacy and promotion is under way to increase the re-use of UCL Discovery content in support of taught courses. 


\section{Conclusion}

UCL Discovery has evolved to become an effective showcase for UCL research. It increasingly supports other parts of the institutional mission, such as campus-based publishing and e-learning. The UCL Discovery team is well positioned to respond to the HEFCE's recently announced Open Access policy (www.hefce.ac.uk/whatwedo/rsrch/rinfrastruct/oa/) for the post-2014 REF.

\section{UCL infrastructure and services for Gold APC payments in the UK context}

\section{Background}

In the wake of the Finch Report (Finch 2012, www.researchinfonet.org/wpcontent/uploads/2012/06/Finch-Group-report-FINAL-VERSION.pdf), and its recommendations in favour of Gold Open Access for publicly-funded research, the UK Research Councils' policy on Open Access was introduced on 1 April 2013. The policy, which applies to peer-reviewed research papers submitted after that date, allows researchers to comply either through the Gold or the Green route, but expresses a preference for Gold (RCUK 2013). A CC-BY licence is required for Gold compliance.

The Research Councils support the policy by awarding block grants to institutions to cover article APCs. The policy sets out a five-year transition to 100\% Open Access for RCUK papers, with a target of $45 \%$ in 2013-14. In the first year, at least 693 RCUK-funded UCL papers had to be published Open Access.

UCL has a thriving institutional repository, UCL Discovery, an Open Access mandate, experience of managing an Open Access block grant for Wellcome Trust papers, and strategic support for Open Access at the highest levels of the institution. It was well placed to respond swiftly and decisively to the new UK Open Access climate, to introduce services to enable researchers to comply with the RCUK policy, and to set up comprehensive support for Gold Open Access.

\section{Establishing Open Access funding services}

At UCL, the choice of Gold or Green Open Access is an academic decision for researchers. Alongside its RCUK and Wellcome Trust budgets, UCL has established a central Open Access fund to support all authors. This enables any UCL researcher to opt for Gold (funds permitting), and allows them to take decisions about their preferred Open Access route on the merits of the case.

Academic freedom is the cornerstone of UCL's Open Access activity. Researchers are "free to choose where to publish, how much to publish, and how often they publish" (RCUK Policy on Open Access to Research: UCL Implementation Guidelines - www.ucl.ac.uk/library/openaccess/rcuk-imp-guide.shtml). To make use of the RCUK funds, papers must either have a UCL corresponding author or UCL RCUK grant-holder, but access to the funds is not restricted to particular faculties, departments or types of researcher.

UCL's Open Access Funding Team now comprises an Open Access Funding Manager, Open Access Compliance Officer (funded from the RCUK block grant) and two Open Access Funding Assistants (one RCUK-funded). Advocacy, publisher liaison and a commitment to providing a flexible, responsive service are key to achieving compliance targets - and to encouraging authors to take advantage of the funds available. 


\section{Advocacy and compliance}

In the past year, UCL has established an extremely successful programme of Open Access advocacy. UCL's Open Access Communication Plan identifies key stakeholders and methods of communicating with them. Between May 2013 and February 2014, the Open Access Funding Manager visited more than 50 different UCL departments and units, and met with individual Heads of Department, Faculty Research Committees and UCL Research Services. The Open Access Compliance Officer undertakes targeted communication with RCUK Principal Investigators (PIs), to make sure that their articles comply with the policy. This has involved liaising with UCL Research Services to identify RCUK-funded PIs, sending e-mails outlining the policy, and checking publication lists to identify RCUK-funded papers. Where the Compliance Officer finds RCUK-funded papers that do not comply, the author is advised to deposit the final manuscript in UCL Discovery, or given the option of Gold Open Access.

Existing channels of communication, such as UCL's e-mail news service, TheWeek@UCL, have been used to make announcements about the RCUK policy and UCL's Open Access Forum (October 2013). UCL's Open Access webpages incorporate a clear design focused on different types of researchers; FAQs and prominent contact details, as well as a feed from the Team's Twitter account, have proved popular.

\section{Open Access funding processes}

UCL's Open Access Funding Team has built a database to record payments, grant data and compliance, and set up systems to monitor licence information. The Team works closely with UCL Discovery to advise on and record Green compliance. Monthly reports track Open Access payments and deposits.

In UCL's experience, third-party systems undoubtedly have the potential to streamline the payment, reporting and compliance processes. UCL is a member of the JISC APC Steering Group, and contributed the first JISC APC Case Study (University College London: A Case Study - www.jisc-collections.ac.uk/Jisc-APC-project/Case-studies/University-CollegeLondon-A-Case-Study). However, in this early phase of Open Access funding management, with publisher APC processes in development and reporting requirements evolving, UCL is keen to simplify the payment process as much as possible. Although some researchers are keen to take advantage of Open Access, others see it as an additional administrative burden. The complex interaction of publisher and funder policies, as well as onerous publisher requirements (form-filling and the like) can discourage authors. In order to maximise academic engagement, UCL has deliberately avoided creating extra work for researchers. The Open Access Funding Team collects information such as paper title, publication, author and grant number(s) and holders(s) by e-mail, since this is how researchers say they prefer to work.

\section{Publisher liaison}

UCL's Open Access Funding Manager works closely with publishers to achieve efficiencies, reduce costs and ease the administrative burden on authors, in particular through prepayment schemes. Under a prepayment arrangement, the institution deposits a lump sum with the publisher, then pays its APCs from the deposited funds at a discounted rate. The discount is typically between $15 \%$ and 30\%. As of August 2014, UCL has 14 prepayment schemes, and is in negotiations with at least five other publishers. Several publishers have introduced prepayment schemes as a direct result of discussions with UCL. Prepayment schemes streamline payment procedures, avoiding individual invoicing for APCs, making it easier for authors to arrange Gold Open Access, and achieving better value for money for institutions. Although some institutions have expressed concern about the transparency of discounts, in UCL's experience most publishers offer standard rates of reduction, which are often tiered according to the level of deposit. 


\section{Future challenges}

RCUK is currently reviewing its Open Access Policy, having collected evidence from institutions on its impact, methods of achieving compliance, licences (especially the CC-BY requirement) and costs. Meanwhile, UCL is confident of meeting the increased requirement of $53 \%$ compliance in 2014-15, having more than met its Year 1 target of $45 \%$ compliance. The introduction of the HEFCE Open Access requirement (http://www.hefce.ac.uk/whatwedo/rsrch/rinfrastruct/oa/) for the next Research Excellence Framework, has raised awareness of Open Access even further, and UCL has laid firm $\begin{array}{lllll}\text { foundations for meeting its targets } 2020 . & \end{array}$

UCL is keen to collaborate with other institutions to achieve efficiencies, develop protocols (for example, on split payments and multi-funder/multi-institution outputs) and engage with other funders. UCL is leading one of the JISC Open Access Pathfinder Projects to explore opportunities for sharing services and developing effective systems to ensure compliance with funders' Open Access policies, and is a key participant in international initiatives, working with other European countries to establish efficient payment systems. The opportunities for embedding Open Access into researchers' workflows, and enabling them to benefit from the increased citations and exposure that result, are immense and exciting.

\section{The Challenge and Potential for UCL Press}

\section{Background to setting up UCL Press}

UCL is ranked 4th in the world's universities (QS World Rankings) and is one of the most successful UK universities at attracting funding, with an income of nearly £900 million in 2012. In that year it received the 3rd highest allocation of RCUK (Research Councils UK) funding.

Despite these accolades, UCL did not have its own press, unlike most other universities of a similar standing in the world. For some years, the UCL Press imprint was licensed to a commercial publisher(s), but no one had published under the imprint since 2007. Dr Paul Ayris, Director of UCL Library Services and now Acting Chief Executive of UCL Press, seized the opportunity to bring the imprint back to its home and to found a new UCL Press at the heart of the institution.

Founding a new university press in the current climate is not an easy task. While some university presses are thriving, many are struggling and indeed some have stopped trading altogether. It is therefore imperative to have a keen awareness of the potential pitfalls and a strong publishing strategy that will differentiate UCL Press from other university presses.

UCL Press plans to be an Open Access and print 'hybrid' publisher, meaning that all its books will be made available free online, but will also be sold in print-on-demand editions and as innovative consumer e-books at very reasonable prices. In the first instance, its main publishing activity will be scholarly monographs and textbooks by UCL academics, but the aim is to widen that out to non-UCL authors and to other genres of publishing. UCL Press is funded for the first three years from UCL's research budget, with the aim after that of recouping production and marketing costs through sales of print-on-demand editions. UCL Press plans to start publishing later in 2015. 


\section{Challenges}

\section{Being a start-up}

Any start-up publisher has the challenge of attracting authors when it is as yet unproven. Authors wonder what kind of quality control is in place, what kind of editorial and marketing service they will get, what the production values of their book will be, whether their book will get reviewed, and whether their work will be taken seriously. Academics worry that their institutional publisher will be seen as a vanity press, a publisher of last resort when they cannot get their book published by an established press.

\section{Open Access}

Open Access is a relatively new publishing model and still attracts a lot of misconceptions and mistrust. Authors think that no-one will be able to find their book, that it will not be subject to the same degree of peer review and quality control as a printed book, that it will be easier to pirate, and that they will lose control of their copyright. And what will the effect be on the versions of the book that are made available commercially?

\section{Publishing model - are we a publisher or a service?}

Being a publisher for an institution brings its own set of unique challenges, principally: are we here to build a publishing programme of great repute, by being highly selective about what we publish and actively seeking out high-profile academics and projects? Or are we here to provide a publishing service to our academics, which means that as long as the book is given the seal of approval via the peer review process, then the institution will publish it?

\section{Measures of success}

When commercial considerations are removed, which are the usual indicators of the success of a book (e.g. sales figures and revenue), what are the measures of success? These need to be clearly identified and could include download and citation figures, reviews in the press, take-up by students of textbooks, and sales of the Print-on-Demand (PoD) edition.

\section{Potential}

\section{UCL as an institution}

UCL is London's Global University, with innovative approaches to research, teaching and learning. The ground-breaking work of its researchers is regularly in the news and provides solutions to some of the world's most challenging problems. UCL Press is in an excellent position to publish books that reflect the innovation and expertise of the institution. By stating this as one of its chief aims, it is hoped that ULC academics will be encouraged to publish their best work with UCL Press.

\section{Diversity of UCL's activities, including Grand Challenges}

As well as traditional Faculties, UCL has a number of Schools, projects and crossdisciplinary centres, many of them born out of UCL's innovative approach to research, the Grand Challenges, which was launched in 2008. These include CREDOC (The UCL Centre for Research on the Dynamics of Civilisation), the UCL Centre for the Study of DecisionMaking Uncertainty and the Equiano Centre for Research into the Black History in Britain and theories of race. UCL also has the Slade School of Art, the Institute of Making, its own Art Gallery, and several museums including the Grant Museum of Zoology and the Petrie Museum of Egyptian Archaeology. With such rich pickings on its doorstep, UCL Press can build up a publishing programme that will be different from the typical university press model. 


\section{Benefits of Open Access and electronic publishing}

UCL is committed to Open Access publishing. Open Access increases the usage, visibility and impact of research and makes it available to all through free, unrestricted Open Access. With the problems associated with traditional monograph publishing, UCL Press has decided to make all its publications Open Access at the outset. There is also an opportunity to create innovative publishing models using enhanced digital techniques that integrate words, image, video and audio.

\section{Business model}

One of the challenges of Open Access publishing is that it does not fit the traditional commercial business model of recouping costs through typical sales channels. Other ways of covering costs are therefore required, such as BPCs (Book Publishing Charges, met by the funder, the individual or the institution), recouping costs by selling print editions alongside the Open Access version, or financial support from the institution. UCL Press is very lucky to be fully funded for the first three years, and can therefore use this time to focus on establishing a publishing programme of excellence.

\section{Conclusion}

While there are undoubtedly challenges involved in setting up a new university press with a relatively untried business model, UCL has the advantages of being an institution of great renown which will lend authority to the UCL Press brand, as well as the financial support and the will to make it a thriving concern.

\section{Going Forwards}

The UK has a strong policy position on Open Access. The Finch Report, the RCUK OA policy and the new REF 2020 mandate from HEFCE have changed the OA landscape, with the HEFCE OA policy requirements likely to be a game changer.

UCL Discovery is making a strong showing as UCL's institutional repository. Open Access research theses are an important part of the repository's contents. The publication of the HEFCE REF 2020 Open Access requirement is a 'game changer' as far as the penetration of repository work in UK universities is concerned.

The UK has taken an almost unique position in Open Access policy by preferring Gold as opposed to Green as a route for Open Access dissemination. UCL has met its target for compliance for Gold OA funding from RCUK, and is now poised to meet the challenge of the REF 2020 OA requirement laid down by HEFCE.

The creation of an Open Access UCL Press creates an opportunity for UCL to maximise visibility to the research outputs which the institution produces. Monographs are at the core of this new publishing activity and innovation in delivery underlines the work of the Press in this space.

Throughout, UCL sees Open Access as an opportunity, not a threat. True to its history of radical innovation, UCL has embraced Open Access and is using it to support researchers and to maximise the visibility of the institution on a global stage. 


\section{References}

Ayris, P., 'Paying Twice for Gold' ScienceGuide February 5, 2014, accessed June 62014 , http://discovery.ucl.ac.uk/1418707/1/Ayris Paying twice for Gold.pdf and http://www.scienceguide.nl/201402/paying-twice-for-gold.aspx.

LERU Open Access Working Group. June 2011. The LERU Roadmap towards Open Access. LERU Advice Paper No. 8. LERU.

QS World University Rankings 2013/14. 2014. “Top Universities.” QS World University Rankings 2013/14. Accessed June 10. http://www.topuniversities.com/universityrankings/world-universityrankings/2013\#sorting=rank+region $=+$ country $=+$ faculty $=+$ stars=false + search

Poynder, R., "The Finch Report in a global Open Access landscape?" Open and Shut, June 25, 2012, accessed June 10, 2012, http://poynder.blogspot.com.es/2012/06/finch-report-inglobal-open-access.html

Poynder, R. 2012 “The Finch Report: UCL's David Price responds", Open and Shut, June 19, 2012, accessed June 10, 2012, http://poynder.blogspot.com.es/2012/06/finch-reportucls-david-price-responds.html

Swan, A., and Houghton, J., 2012. Going for Gold? The Costs and Benefits of Gold Open Access for UK Research Institutions: Further Economic Modelling. Report to the UK Open Access Implementation Group. Jisc. http://repository.jisc.ac.uk/610/. 